Goldschmidt 2021 Abstract

https://doi.org/10.7185/gold2021.8264

\title{
CO2 favours the accumulation of excess fluids in felsic magmas
}

\author{
MATTIA PISTONE ${ }^{1}$, LUCA CARICCHI ${ }^{2}$ AND PETER \\ ULMER $^{3}$
}

\author{
${ }^{1}$ University of Georgia \\ ${ }^{2}$ University of Geneva \\ ${ }^{3}$ ETH Zürich \\ Presenting Author: Mattia.Pistone@uga.edu
}

Volcano deformation and gas emissions provide insights into subsurface magmatic systems. Large discrepancies are observed between the volumes calculated from deformation data, mass of emitted gases, and volumes of erupted magmas. Such discrepancies hinder our capacity to predict the magnitude and intensity of imminent eruptions and are ascribed to the amount of excess fluids stored in magma reservoirs. High-pressure (1240 bar) and high-temperature $\left(1200{ }^{\circ} \mathrm{C}\right)$ hot isostatic press experiments show that the amount of trapped excess fluids in haplogranitic magmas with variable crystal contents (30, 50, 60, and 70 vol.\%) depends strongly on fluid composition. Magmas with CO2 excess fluids become permeable at much larger porosities (44\% higher) with respect to the H2O-rich counterparts at equivalent crystallinity. Available excess gas geochemistry data calculated from volatile-saturated melt inclusion record, syn-eruptive SO2 emission, and erupted juvenile porosity data collected for crystal-rich andesite and crystal-poor dacitelrhyolite volcanoes with known eruption magnitude and intensity (Mt St Helens 1980, Pinatubo 1991, Soufriére Hills 1996, and Merapi 2010) reveal that the discrepancy between erupted magma volume and $\mathrm{SO} 2$ released during the eruption increases with $\mathrm{CO} 2$ excess in magmas. In agreement with our experiments, these data highlight that CO2rich fluids enhance magma's capacity to store excess volatiles and shed light on the largest discrepancies between pre-eruptive deformation, gas emissions, and eruption intensity and magnitude. 